\title{
KID syndrome: About a case
}

\section{Kaoutar Achehboune, Khadija Elboukhari, Selma Kadiri, Hanane Baybay, Sara Elloudi, Fatima Zahra Mernissi}

\author{
Department of Dermatology, University Hospital Hassan II, Fez, Morocco
}

Corresponding author: Dr. Kaoutar Achehboune, E-mail: achehboune.kaoutar@gmail.com

\begin{abstract}
KID syndrome is a rare autosomal dominant genetic disorder, due to a lack of keratinization. Rarely sporadic. It is manifested by the main triad; keratitis ictyosis and deafness. cutaneous manifestations are detected at birth or a little later in the neonatal period, while ocular and auditory manifestations are later detected during childhood or adolescence to varying degrees, although they are present at the birth. The management of this pathology is difficult with a risk of deafness generally severe, and a definite blindness. Regarding cutaneous involvement, management is based mainly on topical symptomatic treatment based on emollient creams and the hygiene of life, and sometimes systemic retinoids are used in severe forms. We report an observation of a Moroccan patient of 18 years.
\end{abstract}

Key words: KID syndrome; Keratitis; Deafness; Ichthyosis; Genetic

\section{INTRODUCTION}

Keratitis-Ichthyosis-Deafness Syndrome (KID) is a rare genodermatosis by the triad: keratitis, ictyosis and deafness. It is due to a mutation of the gene 26 connection [1]. Less than 100 have been reported in the literature [2]. We report a case.

\section{CASE REPORT}

18-year-old patient from a non-consanguineous marriage does not present a similar case in the family, which has had generalized erythema since the age of 2 months, with dry and diffuse skin lesions. He consulted for diffuse cutaneous lesions with a deafness and a decrease of visual acuity and photophobia of progressive worsening with a fall of the hairs of the body. Clinical examination found diffuse ichtyosis and palmoplantar keratosis, follicular keratosis (Figs. 1 and 2), scarred alopecic scalp plaques (Fig. 3), eyelash and eyebrow depilation (Fig. 1), the examination of the oral mucosa finds a geographic tongue (Fig. 4), and ophthalmologic examination revealed keratitis with neovascularization of the horny. And deafness of bilateral clinical perception confirmed on audiometry.
The patient was treated with emollients and creams based on urea, in parallel with the ophthalmological measures with a good improvement of the skin condition.

\section{DISCUSSION}

The syndrome of the child is described as early as 1915 by Burns [3]. It is a problem of cornification, rare, autosomal dominant. Rarely sporadic; this is the case of our patient. This ectodermal dysplasia is due to a mutation in the gene encoding connexin 26 (GJB2) that causes keratitis, ichtyosis and neurosensory deafness $[2,4]$. This disease usually appears in neonates as generalized erythema, sometimes with diffuse scaling and leathery skin. Typical skin changes gradually develop during infancy and include linear and spiny hyperkeratosis of the flexures, and ichthyosis-hystrixlike scaling on the limbs [5]. Some patients develop thick perioral rugae and an aged or leonine appearance of the face [6]. About half of the patients have sparse scalp hair and sparse or often absent eyebrows and eyelashes [7]. Hearing loss, mainly neurosensory, is always present, with variable degrees of compromise. It is congenital but usually detected during infancy

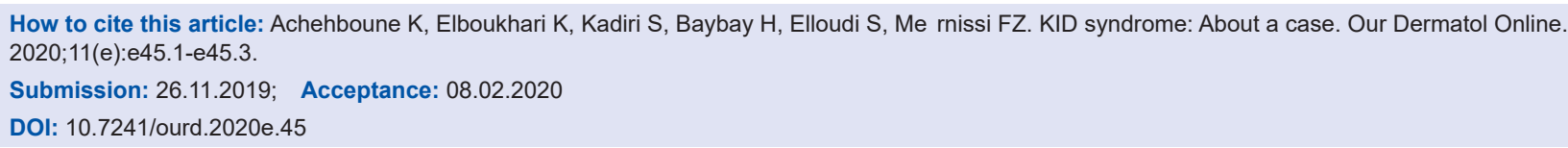




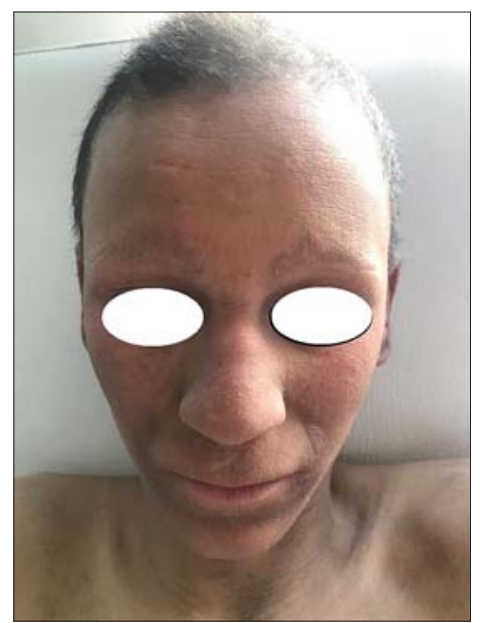

Figure 1: Spiny follicular ichthyosis, with eyelash and eyebrow depilation.

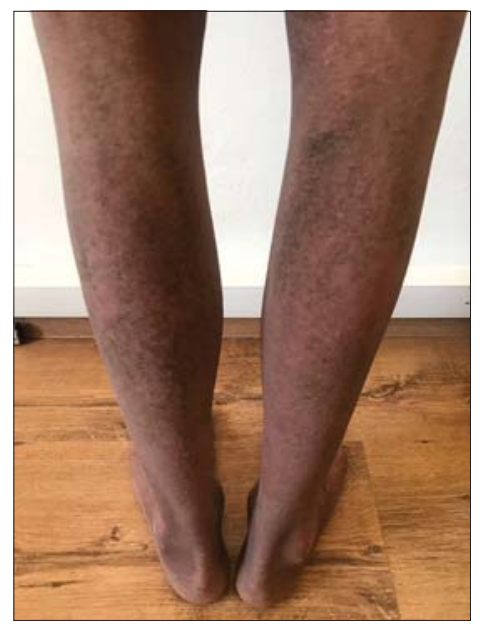

Figure 2: Diffuse ichthyosiform dander.

or early childhood, and has almost always developed by age 7 years. Because of neurosensory deafness, speech development is usually delayed [5]. The ocular manifestations usually are progressive and develop during childhood or early adolescence. The ocular manifestations usually are progressive and develop during childhood or early adolescence [8]. The search for the genetic mutation can contribute to the diagnosis. Pancreatic, cutaneous and mucosal carcinomas and super infections are the main complications with risk of death during neonatal wager $[1,4]$. Deafness is usually severe. Ophthalmological involvement can lead to blindness [3]. Psychosocial reintegration is important. Treatment is based on symptomatic topical treatment, antifungals and antibiotics with systemic retinoids [1]. Although systemic retinoids have been used in several patients with variable success, to date there is no consensus on their benefits in KID syndrome. Isotretinoin has aggravated keratitis

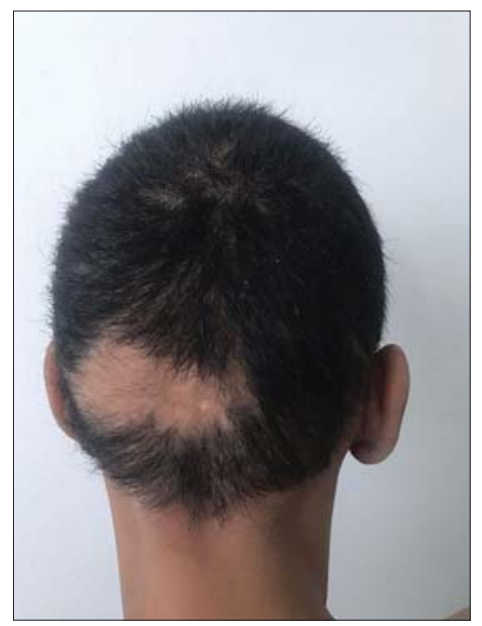

Figure 3: Alopecic scar plate of the scalp.

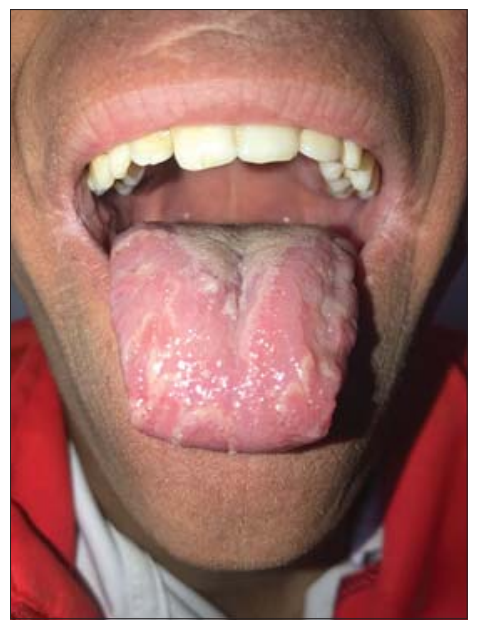

Figure 4: Geographic tongue.

in one patient. We think that, along with urgent ophthalmologic and otolaryngologic measures, simple topical therapies may improve skin condition in KID syndrome precluding the possible hazards of systemic therapy [9]. The complications justify the aggressive treatments. Hence the importance of screening and treatment adapted to the long run.

\section{CONCLUSION}

The syndrome of the child is a rare affection, the diagnosis is clinical, the aesthetic, functional and sometimes vital damage. The price in charge is early and post-monitoring-to-long process in order to detect and treat complications.

\section{Consent}

The examination of the patient was conducted according to the Declaration of Helsinki principles. 
The authors certify that they have obtained all appropriate patient consent forms. In the form the patient(s) has/have given his/her/their consent for his/ her/their images and other clinical information to be reported in the journal. The patients understand that their names and initials will not be published and due efforts will be made to conceal their identity, but anonymity cannot be guaranteed.

\section{REFERENCES}

1. Coggshall K, Farsani T, Ruben B. Keratitis, ichthyosis, and deafness syndrome: a review of infectious and neoplastic complications. J Am Acad Dermatol. 2013;69:127-34.

2. Patel V, Sun G, Dickman M, Khuu P, Teng JM. Treatment of keratitis-ichthyosis- deafness (KID) syndrome in children: a case report and review of the literature. Dermatol Ther. 2015;28:89-93.

3. Coggshall K, Farsani T, Ruben B. Keratitis, ichthyosis, and deafness (KID) syndrome: A review of infectious and neoplastic complications. J Am Acad Dermatol. 2013;69:127-34.

4. Elsayed SM, Seifeldeen NS, Bolz H. Connexin 26 (GJB2) mutation in KID syndrome: An Egyptian patient. Egyptian J Med Human Genet. 2011;12:91-3.

5. Langer K, Konrad K, Wolff K. Keratitis, ichthyosis and deafness (KID) syndrome: report of three cases and a review of the literature. Br J Dermatol. 1990;122:689-97.

6. Rycroft RJG, Moynahan EJ, Wells RS. Atypical ichthyosiform erythroderma, deafness and keratitis: a report of two cases. Br J Dermatol. 1976;94:211-17.

7. Sinsh K. Keratitis, icthyosis and deafness (KID) syndrome. Aust. J. Dermatol. 1987;28:38-41.

8. Ahmadi S, McKenna K. Keratitis-ichthyosis-deafness syndrome and carotenaemia. Clin Exp Dermatol. 2003;28:394-6.

9. Abdollahi A, Hallaji Z, Esmaili N, Valikhani M, Barzegari M, Akhyani M, et al. KID syndrome. Dermatol Online J. 2017;13:11.

Copyright by Kaoutar Achehboune, et al. This is an open-access article distributed under the terms of the Creative Commons Attribution License, which permits unrestricted use, distribution, and reproduction in any medium, provided the original author and source are credited.

Source of Support: Nil, Conflict of Interest: None declared. 